\title{
Indications and Risks of Fibrinogen in Surgery and Trauma
}

Stein, Philipp ; Spahn, Gabriela ; Spahn, Donat

DOI: https://doi.org/10.1055/s-0035-1564841

Posted at the Zurich Open Repository and Archive, University of Zurich ZORA URL: https://doi.org/10.5167/uzh-127770

Journal Article

Accepted Version

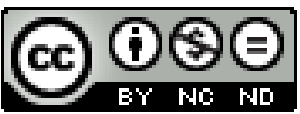

The following work is licensed under a Creative Commons: Attribution-NonCommercial-NoDerivatives 4.0 International (CC BY-NC-ND 4.0) License.

Originally published at:

Stein, Philipp; Spahn, Gabriela; Spahn, Donat (2016). Indications and Risks of Fibrinogen in Surgery and Trauma. Seminars in Thrombosis and Hemostasis, 42(02):147-154.

DOI: https://doi.org/10.1055/s-0035-1564841 


\title{
Indications and Risks of Fibrinogen in Surgery and Trauma.
}

\author{
Donat R. Spahn M.D., F.R.C.A. ${ }^{1}$, Gabriela H. Spahn M.D. ${ }^{2}$, \\ Philipp Stein M.D. ${ }^{3}$ \\ ${ }^{1}$ Professor and Chairman, Institute of Anesthesiology, University and University \\ Hospital of Zurich, Zurich, Switzerland \\ ${ }^{2}$ Research Associate, Institute of Anesthesiology, University and University Hospi- \\ tal of Zurich, Zurich, Switzerland \\ ${ }^{3}$ Staff member, Institute of Anesthesiology, University and University Hospital of \\ Zurich, Zurich, Switzerland
}

\author{
Address for correspondence: \\ Donat R. Spahn, MD, FRCA \\ Professor and Chairman \\ Institute of Anesthesiology \\ Section Head Medical \\ Anesthesiology - Intensive Care Medicine - OR-Management \\ University of Zurich and University Hospital Zurich \\ Raemistrasse 100 \\ $\mathrm{CH}-8091$ Zurich, Switzerland \\ Phone: +4144255 2695 \\ FAX: +41442559593 \\ E-Mail: donat.spahn@usz.ch
}




\section{Abstract}

Fibrinogen has a central role in coagulation. Following trauma and perioperatively low fibrinogen levels have been found to be risk factors for exaggerated bleeding, transfusion needs and adverse outcome. Conversely, treatment with exogenous fibrinogen in critically bleeding patients with low fibrinogen levels has been shown to decrease transfusion needs. Since following trauma and in many perioperative situations fibrinogen is the first coagulation "element" to become critically low, it appears reasonable to target fibrinogen in clinical coagulation algorithms aiming at early specific and goal-directed treatment. A low fibrinogen can be a low plasma concentration or a low functional fibrinogen as assessed by point-of-care techniques like thromboelastography or thromboelastometry. This review summarizes the evidence base for perioperative algorithm based fibrinogen administration including the exact thresholds for fibrinogen administration used in the different algorithms. Algorithm based individualized goal-directed use of fibrinogen resulted in highly significant reduction of transfusion needs, adverse outcomes, in certain studies even mortality and where investigated reduced costs, with high safety levels at the same time. Best evidence exists in cardiac surgery, followed by trauma, postpartum hemorrhage and liver transplantation. The introduction of these concepts is highly demanding and requires a tremendous educational effort to familiarize all health care workers with the necessary knowledge and the skills of how to run thromboelastometry / thromboelastography tests. Future research is needed to compare the efficacy, safety and costs of different al- 
gorithms. This, however, should not prevent us from introducing these expedient point-of-care based algorithms clinically today.

Keywords: Fibrinogen, Blood Coagulation, Algorithms, Patient Blood Management 


\section{Introduction}

Fibrinogen has a central role in coagulation. It links platelets and is the substrate of the plasmatic coagulation resulting in a mesh network which is essential for clot strength ${ }^{1-3}$. Following trauma ${ }^{4-8}$ and perioperatively ${ }^{9-13}$ low fibrinogen levels have been found to be risk factors for exaggerated bleeding, transfusion needs and adverse outcome. Conversely, treatment with exogenous fibrinogen in critically bleeding patients with low fibrinogen levels has been shown to decrease transfusion needs highly significantly ${ }^{10,14-17}$. Fibrinogen molecules are consumed for the developing clot whereas most other coagulation factors are reusable enzymes. Therefore fibrinogen is the first coagulation factor to become critically low during activation of coagulation and bleeding ${ }^{18-20}$.

Consequently targeting fibrinogen as a central element in critical bleeding for early specific and goal-directed treatment appears reasonable. The optimal way of quickly detect critically low fibrinogen levels, however, is still a matter of debate. At certain centers laboratory based fibrinogen concentration measurements are the only way of detecting low fibrinogen levels. However, turnaround times of 60$90 \min ^{21,22}$ are too high in a critically bleeding patient, fibrinogen concentration measurements vary by up to $80 \%$ between laboratories ${ }^{23}$ and may be influenced by the presence of artificial colloids ${ }^{24,25}$. Hence thromboelastographic/thromboelastometric techniques are increasingly used to monitor coagulation quickly following trauma and during critical bleeding perioperatively 4,5,10,12,15-17,26. These monitoring techniques allow a comprehensive evaluation of the coagulation within 10-20 min with a specific focus on fibrinogen activity including the compromis- 
ing effect of artificial colloids on coagulation ${ }^{25,27-30}$. In the following a "low fibrinogen level" thus may be based on a low fibrinogen concentration measured in the central laboratory or a low fibrinogen activity based on thromboelastographic / thromboelastometric evaluation.

While some may argue that the evidence is still limited justifying the use of fibrinogen for the early goal-directed treatment of coagulopathy or critical bleeding ${ }^{31}$, we are going to present the emerging concepts in different fields of trauma and surgery including their limitation and safety aspects. We are also going to characterize the difference between the prospective randomized study vs. a pragmatic algorithm introduction approach in the complex and highly dynamic field of coagulopathy and critical bleeding ${ }^{32,33}$.

\section{Trauma}

Trauma is a major health care issue resulting in the annual death of 5-8 million people worldwide ${ }^{20}$. Bleeding in trauma is due to vascular damage but in approximately $30 \%$ of patients also due to coagulopathy of trauma ${ }^{20,34,35}$ which develops already at scene before any medical intervention ${ }^{36}$ and which results in a several fold increased mortality ${ }^{34,35,37}$. Besides hyperfibrinolysis ${ }^{20,38-40}$ a low fibrinogen level is the hallmark of the coagulopathy of trauma ${ }^{4-8,20,41}$.

Early detection and characterization of coagulopathy following trauma is essential for early goal-directed treatment based on algorithms ${ }^{33}$. Such algorithms go far beyond describing indications for the administration of fibrinogen. They rather define the type of coagulation monitoring used and the treatment of all significant 
alterations of the coagulation system following trauma including targets for the interior milieu $(\mathrm{pH}$, temperature, and hemoglobin level), the administration of tranexamic acid, prothrombin complex concentrate (PCC), factor XIII and labile allogeneic blood products such as red blood cells, plasma and platelets ${ }^{20,26,42}$. In addition, such point-of-care based algorithms also define when and how to monitor the success of the initiated treatment and how to capture the evolution of the case over time. This is particularly important in the highly dynamic period following trauma. Fibrinogen is a key element in such algorithms (table 1) but the success cannot be ascribed to one single measure. Nevertheless such algorithms are successful in improving coagulation tests ${ }^{43}$ reducing the need for allogeneic blood transfusions ${ }^{15,16,44}$, reducing the incidence of post-traumatic multiorgan failure, shortening length of hospital stay ${ }^{16}$ and they may improve survival 15,17. The recent study of Nardi et al. ${ }^{15}$ deserves special mentioning. They describe the institutional switch from a rigid 1:1 RBC:plasma transfusion scheme to an individualized thromboelastometry and fibrinogen / PCC based early treatment algorithm. With this algorithm they could decrease transfusions of allogeneic blood products highly significantly with a trend towards improved survival ${ }^{15}$.

At current time, we are unaware of a prospective randomized study assessing the effect of the administration of fibrinogen in trauma patients. However, there is a prospective randomized study in trauma patients comparing a 1:1:1 RBC:plasma:platelet transfusion scheme with a laboratory based individualized treatment algorithm ${ }^{45}$. Although conceptualized as a feasibility trial Nascimento 
at al. found a near significant two-fold reduction in mortality from $32 \%$ to $14 \%$ of patients treated according to an individualized treatment algorithm ${ }^{45}$.

The use of algorithms or the administration of fibrinogen has to our knowledge not resulted in any specific adverse effect in trauma. However, some wonder, whether the administration of exogenous fibrinogen would not result in exaggerated high postoperative / posttraumatic fibrinogen levels. Post-traumatic fibrinogen levels indeed increase significantly in the first week but this increase is not any higher in patients treated with exogenous fibrinogen during the initial treatment ${ }^{46}$.

\section{Cardiac surgery}

The success of a thromboelastometry, fibrinogen and PCC based coagulation algorithm was first shown in a single center study by Görlinger et al. ${ }^{47}$. They compared the traditional period before (2004) with the period after the introduction of their algorithm (2009) and found a significant reduction in the use allogeneic blood products by $20 \%$, particularly RBC (-19\%) and plasma (-94\%) with a slight but significant increase in platelet transfusion (+29\%); at the same time, however, the percentage of patients on dual platelet antagonists increased by

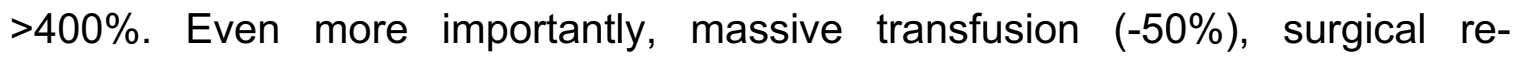
exploration (-47\%) and thrombotic adverse events (-45\%) decreased significantly 47. A similar algorithm was then tested in a prospective randomized 2-center trial in patients with diffuse bleeding after cardiopulmonary bypass and heparin reversal against a traditional algorithm (table 1) ${ }^{48}$. Again, a highly significant reduction 
on RBC transfusions (from 5 to 3 ) and plasma (from 5 to 0 ) and the use of recombinant factor VIla (from $24 \%$ to $2 \%$ ) was found while the use of fibrinogen concentrate was similar in both groups. Interestingly also the total costs of hemotherapy (factor concentrates, allogeneic blood products and coagulation test costs) were significantly reduced from 3'109 Euro to 1'658 Euro per patient. The most important findings, however, were a significantly reduced rate of adverse events (from $38 \%$ to $8 \%$ ) and a reduction in 6 month mortality (from $20 \%$ to $4 \%$ ) in patients treated by the thromboelastometry, fibrinogen and PCC based coagulation algorithm ${ }^{48}$. Also in patients after aortic surgery with clinically relevant coagulopathic bleeding after cardiopulmonary bypass and heparin reversal, the effect of high dose fibrinogen administration based on thromboelastometry resulted in a highly significant reduction in total exposure to allogeneic blood products from 13 to 2 units per patient and a concomitant increase of the percentage of patients totally avoiding any blood products form $0 \%$ to $45 \%{ }^{49}$. In this study no trigger level for the administration of fibrinogen was used but a thromboelastometry test (FIBTEM) was done 20 min prior to the end of cardiopulmonary bypass. Based on this test and aiming for a FIBTEM MCF of $22 \mathrm{~mm}$ the individual dose of fibrinogen (median $8 \mathrm{~g}(\mathrm{IQR} 6-9 \mathrm{~g})$ ) was calculated. In general complex cardiac surgery the same approach was followed in a recent prospective randomized double-blind study in 116 patients ${ }^{50}$. Also in this study the percentage of patients avoiding all allogeneic blood products was significantly higher (67\% vs. $45 \%)$ and the amounts of RBCs, plasma and platelet transfused as well as postoperative bleeding was significantly lower in the treatment $\mathrm{arm}^{50}$. 
There are also prospective randomized studies on the prophylactic use of fibrinogen in cardiac surgery. Karlsson et al. found in a small study of 20 patients that a preoperative $2 \mathrm{gr}$ dose of fibrinogen (vs. placebo) in patients undergoing CABG surgery reduced postoperative blood loss and increased the $\mathrm{Hb}$ concentration at postoperative day one without effect on transfusion rate ${ }^{51}$. A similar approach was chosen by Sadeghi et al. ${ }^{52}$. In 60 patients undergoing CABG surgery they administered $1 \mathrm{gr}$ of fibrinogen (vs. placebo) after anesthesia induction and found reduced postoperative bleeding. There was a trend towards fewer patients needing postoperative RBC transfusions but the difference was not statistically significant ${ }^{52}$. Finally, Tanaka et al. studied 20 patients following valve surgery with signs of coagulopathic bleeding ${ }^{53}$. They compared a $4 \mathrm{~g}$ dose of fibrinogen vs. the administration of one unit of apheresis platelets. Patients in the fibrinogen group received fewer platelet transfusions and had a lower total donor exposure than patients in the platelet group ${ }^{53}$.

No safety issues have been detected in any of the above studies. In contrast, in two studies a significant reduction of major adverse events was found ${ }^{47,48}$ and in one study even mortality was significantly reduced ${ }^{48}$. A minor issue is the question of whether the intraoperative administration of fibrinogen would result in exaggerated fibrinogen levels postoperatively. This has been specifically assessed and clearly shown that the postoperative fibrinogen levels similarly in patients with and without intraoperative fibrinogen administration ${ }^{54}$.

Until today it is unclear which algorithm element (thrombelastometry, fibrinogen or PCC administration) is most important for the success. Interestingly, already 
the implementation of any type of thromboelastography and thromboelastometry coagulation algorithm results in a significant reduction in the use of allogeneic blood products in cardiac surgery ${ }^{55-57}$. Nevertheless the study by Weber et al., in which an algorithm using primarily fibrinogen and PCC rather than plasma and platelets resulting in improved outcome, indicates that factor concentrates may significantly contribute to the observed benefit in reduced major adverse events and improved survival ${ }^{48}$. Another important aspect of such advanced coagulation algorithms is the repeated monitoring of the coagulation status of the patient. This allows early and specific intervention with a sufficient but moderate dose. The effect is then quickly verified and additional drugs may be given if necessary. In any case an overtreatment with consecutive hypercoagulability is avoided which may explain a reduction in thrombotic complications in some of the studies $47,48$.

A study similar the one of Rahe-Meyer et al. ${ }^{49}$ has recently been performed in aortic surgery as a prospective randomized multi-center study (https://clinicaltrials.gov/ct2/show/NCT01475669, accessed June 21, 2015). However, at current time the results have not been formally published.

\section{Liver surgery and transplantation}

Liver transplantation remains an operation with major blood loss and substantial need of allogeneic blood product transfusion, because blood coagulation is altered and often compromised in the recipient ${ }^{58-63}$. Since blood loss and blood product transfusions remain significant independent risk factors for mortality and 
adverse outcome ${ }^{64}$, ways of detecting and characterizing coagulation problems using thromboelastography / thromboelastometry have been sought since many years (table 1) ${ }^{61,62,65}$. Thromboelastography / thromboelastometry, fibrinogen and PCC based algorithms were developed and resulted in conflicting results: Rollet et al. could not decrease their need for allogeneic blood products ${ }^{60}$, while Leon-Justel et al. succeeded in reducing their transfusion needs highly significantly ${ }^{66}$. Kirchner et al. have shown the safety of such a treatment concept. They searched prospectively for hepatic artery and portal vein thrombosis, pulmonary embolism, stroke and myocardial infarction and did not find a difference between the groups ${ }^{58}$.

To our knowledge, there are no prospective randomized studies on the efficacy of fibrinogen in liver surgery and transplantation published.

\section{Postpartum hemorrhage}

Postpartum hemorrhage (PPH) is a major cause of maternal morbidity and mortality worldwide ${ }^{67,68}$ and the incidence is increasing in the Western countries ${ }^{69,70}$. $\mathrm{PPH}$ has recently be defined as "active bleeding of $>1$ '000 $\mathrm{ml}$ within the 24 hours following birth that continues despite the use of initial measures including first-line uterotonic agents and uterine massage" ${ }^{71}$. Pathophysiology of PPH is a combination of the following main factors: Uterine atony, trauma to the birth canal, placental problems (retained, abnormal implantation) and coagulopathy characterized by hyperfibrinolysis and low fibrinogen ${ }^{71,72}$. For non-obstetricians it is important to understand that all these factors are present and intertwined, and as a 
consequence, need to be addressed at the same time, ideally in a common algorithm between obstetricians, anesthesiologists and hematologists. Equally important is implementing a process to detect women with PPH early.

The first step in the treatment of PPH related coagulopathy is to stop hyperfibrinolysis with tranexamic acid. A first pivotal study was performed by DucloyBouthors et al. in women with $>800 \mathrm{ml}$ of $\mathrm{PPH}^{73}$. Women randomized to receive $4 \mathrm{gr}$ of tranexamic acid had less blood loss, less progression to severe PPH and received fewer RBC transfusions. Based on this and many other studies the World Health Organization recommends treating women with PPH with tranexamic acid (http://apps.who.int/iris/bitstream/10665/75411/1/9789241548502 eng.pdf?ua=1, accessed June 21, 2015). The optimal dose of tranexamic acid is unknown at the current time but $1-2$ gr may be adequate ${ }^{72}$. The WOMEN trial in $15^{\prime} 000$ women with PPH is using assessing a dose of $1 \mathrm{gr}$ followed by $1 \mathrm{gr}$ if bleeding continues 74. This study is still recruiting (https://clinicaltrials.gov/ct2/results?term=NCT00872469\&Search=Search, accessed June 21, 2015).

A low fibrinogen level was first detected as an independent risk factor for the development of severe PPH in $2007^{75}$. A fibrinogen concentration $<2 \mathrm{~g} / \mathrm{l}$ predicted severe $\mathrm{PPH}$ with a positive predictive value of $100 \%{ }^{75}$. However, the association of a low fibrinogen level with PPH has been challenged recently ${ }^{76}$. Nevertheless fibrinogen treatment in severe PPH was at least as efficacious as the administration of cryoprecipitate ${ }^{77}$. 
Also in PPH, thromboelastography / thromboelastometry guided algorithms are feasible, efficient and successful. Such an algorithm has been published recently (table 1$)^{10}$. By the implementation of their algorithm Mallaiah et al. succeeded highly significantly in decreasing the total number of allogeneic blood products and major adverse outcomes in women with at least 1'500 $\mathrm{ml}$ of blood loss after delivery ${ }^{10}$.

At current time there is only one prospective randomized study addressing fibrinogen application in patients with $\mathrm{PPH}^{78}$. Wikkelso et al. randomized 249 patients with $\mathrm{PPH}$ to receiving a pre-emptive dose of $2 \mathrm{gr}$ fibrinogen or placebo. The fibrinogen concentration before treatment was $4.5 \mathrm{~g} / \mathrm{l}$ in both groups which is normal for pregnant women ${ }^{76,79}$. Since largely women without coagulopathy were included, transfusion outcome was identical in both groups ${ }^{78}$. A clinically more relevant prospective randomized study is underway ${ }^{80}$ in which women with severe $\mathrm{PPH}$ and signs of (low) fibrinogen related coagulopathy in thromboelastometry after treatment with tranexamic acid $(1 \mathrm{gr})$ will be randomized to receive fibrinogen (4-8 gr) or placebo ${ }^{80}$. Despite the formal lack of high-quality proof of efficacy of fibrinogen treatment in severe PPH in women with low fibrinogen levels and / or signs of fibrinogen related coagulopathy, fibrinogen is recommended by the PPH-Consensus Group in Europe ${ }^{81,82}$.

\section{Risk}

Safety issues and specific benefits in the various surgical settings and following trauma have been presented in the respective chapters above. In addition, pre- 
clinical safety animal data was published ${ }^{83}$ and also extensive post-marketing pharmacovigilance data was analyzed recently ${ }^{84}$. Over a period of 27 years and over 2'611'294 g of fibrinogen, representing 652'824 patients across a wide range of clinical settings 383 adverse drug reactions were reported ${ }^{84}$. Anaphylaxis and severe allergic reactions were reported in 20 cases. Five fatal outcomes were described but only one case of death was associated with the anaphylactic reaction. There were 28 cases of thromboembolic complications of which 16 were described in the setting of acquired and 12 in congenital fibrinogen deficiency. In 13 of these 16 cases of acquired fibrinogen deficiency, patients received other pro-thrombotic products in complex clinical situations. Finally, there were 21 cases of suspected viral transmission. With the exception of one case with insufficient data, a causal relationship was considered unlikely, because polymerase chain reaction tests were non-reactive (negative) for the concerned batches and other ways of transmission were probable. Such pharmacovigilance data may be criticized for incomplete reporting. However, also the reporting of adverse events due to allogeneic blood transfusion is known to be largely incomplete. In a study on pulmonary adverse effects of allogeneic blood products none of 24 cases of expert adjudicated transfusion related lung injury or transfusion associated circulatory overload was reported to the blood bank ${ }^{85}$. Therefore the incidence of potential side effects cannot be assessed by such analyses. Safety of fibrinogen or thromboelastometry / thromboelastography, fibrinogen and PCC based algorithms can only be assessed in direct comparisons as described in detail in the different surgery chapters above. 


\section{Outlook}

Thromboelastometry / thromboelastography, fibrinogen and PCC based algorithms are highly promising concepts enabling quick and specific treatment of coagulation problems perioperatively and after trauma. However, some argue that these concepts had never been tested prospectively in a randomized, double-blind multi-center study and thus would not be valid. It is certainly crucial to assess efficacy and safety of these concepts. However, the introduction of these concepts is highly demanding and requires a tremendous educational effort to familiarize all health care workers with the necessary knowledge including the skills of how to run thromboelastometry / thromboelastography tests. When achieved, an equally demanding continuous educational effort aiming at maintaining knowledge and skills and a long learning curve start until this concept works at its best. Once all this is achieved, switching back and forth between a traditional allogeneic blood product based treatment concept and a thromboelastometry / thromboelastography and coagulation factor based algorithm is utterly impossible.

Therefore comparing periods before and after introduction (and learning curve) of algorithms is pragmatically more appropriate. An important topic for future studies is the comparison of different intervention thresholds of specific algorithms. One example might be, comparing a maximum clot firmness value in the FIBTEM of 7 $\mathrm{mm}$ vs. $12 \mathrm{~mm}$ in trauma patients. Such types of studies could be performed as a prospective randomized multi-center study. 


\section{Conclusions}

Fibrinogen has a central role in coagulation and low fibrinogen levels are associated with exaggerated bleeding and transfusion needs. Thromboelastopgraphy / thromboelastometry, fibrinogen and PCC based algorithms are capable of decreasing the need for allogeneic transfusions and improving clinical outcome with lower mortality and morbidity in certain situations. This has clearly been shown in cardiac surgery and has a high evidence level in trauma. Interestingly, in liver transplantation the scientific evidence is not so clear, although thromboelastopgraphy / thromboelastometry based treatment algorithms have been introduced over 30 years ago in this very context. In postpartum hemorrhage evidence is emerging that the above mentioned concepts are efficacious as well. Therefore future research is warranted, which, however, should not prevent us from introducing these expedient point-of-care based algorithms clinically now. 


\section{References}

1. Levy JH, Goodnough LT. How I use fibrinogen replacement therapy in acquired bleeding. Blood 2015;125:1387-93.

2. Mannucci PM. Treatment of von Willebrand's Disease. The New England journal of medicine 2004;351:683-94.

3. Furie B, Furie BC. Mechanisms of thrombus formation. The New England journal of medicine 2008;359:938-49.

4. Rourke C, Curry N, Khan S, et al. Fibrinogen levels during trauma hemorrhage, response to replacement therapy, and association with patient outcomes. J Thromb Haemost 2012;10:1342-51.

5. Inaba K, Karamanos E, Lustenberger $\mathrm{T}$, et al. Impact of fibrinogen levels on outcomes after acute injury in patients requiring a massive transfusion. Journal of the American College of Surgeons 2013;216:290-7.

6. Hagemo JS, Stanworth S, Juffermans NP, et al. Prevalence, predictors and outcome of hypofibrinogenaemia in trauma: a multicentre observational study. Crit Care 2014;18:R52.

7. Schochl H, Cotton B, Inaba K, et al. FIBTEM provides early prediction of massive transfusion in trauma. Crit Care 2011;15:R265.

8. Hagemo JS, Christiaans SC, Stanworth SJ, et al. Detection of acute traumatic coagulopathy and massive transfusion requirements by means of rotational thromboelastometry: an international prospective validation study. Crit Care 2015;19:97.

9. Karlsson M, Ternstrom L, Hyllner M, Baghaei F, Nilsson S, Jeppsson A. Plasma fibrinogen level, bleeding, and transfusion after on-pump coronary artery bypass grafting surgery: a prospective observational study. Transfusion 2008;48:2152-8.

10. Mallaiah S, Barclay P, Harrod I, Chevannes C, Bhalla A. Introduction of an algorithm for ROTEM-guided fibrinogen concentrate administration in major obstetric haemorrhage. Anaesthesia 2015;70:166-75.

11. Gielen C, Dekkers O, Stijnen T, et al. The effects of pre- and postoperative fibrinogen levels on blood loss after cardiac surgery: a systematic review and meta-analysis. Interact Cardiovasc Thorac Surg 2014;18:292-8.

12. Collins PW, Lilley G, Bruynseels D, et al. Fibrin-based clot formation as an early and rapid biomarker for progression of postpartum hemorrhage: a prospective study. Blood 2014;124:1727-36.

13. Grottke O, Fries D, Nascimento B. Perioperatively acquired disorders of coagulation. Current opinion in anaesthesiology 2015;28:113-22. 
14. Fenger-Eriksen $C$, Lindberg-Larsen $M$, Christensen $A Q$, Ingerslev $J$, Sorensen B. Fibrinogen concentrate substitution therapy in patients with massive haemorrhage and low plasma fibrinogen concentrations. British journal of anaesthesia 2008;101:769-73.

15. Nardi G, Agostini V, Rondinelli B, et al. Trauma-induced coagulopathy: impact of the early coagulation support protocol on blood product consumption, mortality and costs. Crit Care 2015;19:83.

16. Schochl $H$, Nienaber $U$, Maegele $M$, et al. Transfusion in trauma: thromboelastometry-guided coagulation factor concentrate-based therapy versus standard fresh frozen plasma-based therapy. Crit Care 2011;15:R83.

17. Schoechl H, Nienaber $U$, Hofer $G$, et al. Goal-directed coagulation management of major trauma patients using rotation thromboelastometry (ROTEM)-guided administration of fibrinogen and prothrombin complex concentrate. Crit Care 2010;14:R55.

18. Martini WZ, Chinkes DL, Sondeen J, Dubick MA. Effects of hemorrhage and lactated Ringer's resuscitation on coagulation and fibrinogen metabolism in swine. Shock 2006;26:396-401.

19. Hiippala ST, Myllyla GJ, Vahtera EM. Hemostatic factors and replacement of major blood loss with plasma-poor red cell concentrates. Anesthesia and analgesia 1995;81:360-5.

20. Spahn DR, Bouillon B, Cerny V, et al. Management of bleeding and coagulopathy following major trauma: an updated European guideline. Crit Care 2013;17:R76.

21. Haas T, Fries D, Tanaka KA, Asmis L, Curry NS, Schochl H. Usefulness of standard plasma coagulation tests in the management of perioperative coagulopathic bleeding: is there any evidence? British journal of anaesthesia 2015;114:217-24.

22. Davenport $\mathrm{R}$, Manson $\mathrm{J}$, De'Ath $\mathrm{H}$, et al. Functional definition and characterization of acute traumatic coagulopathy. Critical care medicine 2011;39:2652-8.

23. Solomon C, Baryshnikova E, Tripodi A, et al. Fibrinogen measurement in cardiac surgery with cardiopulmonary bypass: Analysis of repeatability and agreement of Clauss method within and between six different laboratories. Thrombosis and haemostasis 2014;112:109-17.

24. Fenger-Eriksen C, Moore GW, Rangarajan S, Ingerslev J, Sorensen B. Fibrinogen estimates are influenced by methods of measurement and hemodilution with colloid plasma expanders. Transfusion 2010;50:2571-6.

25. Kind SL, Spahn-Nett GH, Emmert MY, et al. Is Dilutional Coagulopathy Induced by Different Colloids Reversible by Replacement of Fibrinogen 
and Factor XIII Concentrates? Anesthesia and analgesia 2013;117:106371.

26. Theusinger OM, Stein P, Spahn DR. Transfusion strategy in multiple trauma patients. Current opinion in critical care 2014;20:646-55.

27. Theusinger OM, Nurnberg J, Asmis LM, Seifert B, Spahn DR. Rotation thromboelastometry (ROTEM) stability and reproducibility over time. Eur J Cardiothorac Surg 2010;37:677-83.

28. Ganter MT, Hofer CK. Coagulation Monitoring: Current Techniques and Clinical Use of Viscoelastic Point-of-Care Coagulation Devices. Anesthesia and analgesia 2008;106:1366-75.

29. Hartog CS, Reuter D, Loesche W, Hofmann M, Reinhart K. Influence of hydroxyethyl starch (HES) 130/0.4 on hemostasis as measured by viscoelastic device analysis: a systematic review. Intensive care medicine 2011;37:1725-37.

30. Whiting D, DiNardo JA. TEG and ROTEM: technology and clinical applications. American journal of hematology 2014;89:228-32.

31. Wikkelso $A$, Lunde $J$, Johansen $M$, et al. Fibrinogen concentrate in bleeding patients. Cochrane Database Syst Rev 2013;8:CD008864.

32. Kozek-Langenecker S, Fries D, Spahn DR, Zacharowski K. III. Fibrinogen concentrate: clinical reality and cautious Cochrane recommendation. British journal of anaesthesia 2014;112:784-7.

33. Spahn DR. TEG(R)- or ROTEM(R)-based individualized goal-directed coagulation algorithms: don't wait - act now! Crit Care 2014;18:637.

34. Frith D, Goslings JC, Gaarder C, et al. Definition and drivers of acute traumatic coagulopathy: clinical and experimental investigations. J Thromb Haemost 2010;8:1919-25.

35. Brohi K, Cohen MJ, Ganter MT, Matthay MA, Mackersie RC, Pittet JF. Acute Traumatic Coagulopathy: Initiated by Hypoperfusion: Modulated Through the Protein C Pathway? Annals of surgery 2007;245:812-8.

36. Theusinger OM, Baulig W, Seifert B, Muller SM, Mariotti S, Spahn DR. Changes in coagulation in standard laboratory tests and ROTEM in trauma patients between on-scene and arrival in the emergency department. Anesthesia and analgesia 2015;120:627-35.

37. Da Luz LT, Nascimento B, Shankarakutty AK, Rizoli S, Adhikari NK. Effect of thromboelastography (TEG(R)) and rotational thromboelastometry $(\operatorname{ROTEM}(R))$ on diagnosis of coagulopathy, transfusion guidance and mortality in trauma: descriptive systematic review. Crit Care 2014;18:518.

38. Brohi K, Cohen MJ, Ganter MT, et al. Acute coagulopathy of trauma: hypoperfusion induces systemic anticoagulation and hyperfibrinolysis. The Journal of trauma 2008;64:1211-7. 
39. Cardenas JC, Matijevic N, Baer LA, Holcomb JB, Cotton BA, Wade CE. Elevated tissue plasminogen activator and reduced plasminogen activator inhibitor promote hyperfibrinolysis in trauma patients. Shock 2014;41:51421.

40. Raza I, Davenport R, Rourke C, et al. The incidence and magnitude of fibrinolytic activation in trauma patients. J Thromb Haemost 2013;11:30714.

41. Davenport R, Brohi K. Fibrinogen depletion in trauma: early, easy to estimate and central to trauma-induced coagulopathy. Crit Care 2013;17:190.

42. Kozek-Langenecker SA, Afshari A, Albaladejo P, et al. Management of severe perioperative bleeding: guidelines from the European Society of Anaesthesiology. European journal of anaesthesiology 2013;30:270-382.

43. Kashuk JL, Moore EE, Johnson JL, et al. Postinjury life threatening coagulopathy: is 1:1 fresh frozen plasma:packed red blood cells the answer? The Journal of trauma 2008;65:261-70.

44. Nienaber $U$, Innerhofer $P$, Westermann $I$, et al. The impact of fresh frozen plasma vs coagulation factor concentrates on morbidity and mortality in trauma-associated haemorrhage and massive transfusion. Injury 2011;42:697-701.

45. Nascimento B, Callum J, Tien $\mathrm{H}$, et al. Effect of a fixed-ratio (1:1:1) transfusion protocol versus laboratory-results-guided transfusion in patients with severe trauma: a randomized feasibility trial. Cmaj 2013;185:E583-9.

46. Schochl H, Voelckel W, Maegele M, Kirchmair L, Schlimp CJ. Endogenous thrombin potential following hemostatic therapy with 4-factor prothrombin complex concentrate: a 7-day observational study of trauma patients. Crit Care 2014;18:R147.

47. Gorlinger K, Dirkmann D, Hanke AA, et al. First-line Therapy with Coagulation Factor Concentrates Combined with Point-of-Care Coagulation Testing Is Associated with Decreased Allogeneic Blood Transfusion in Cardiovascular Surgery: A Retrospective, Single-center Cohort Study. Anesthesiology 2011;115:1179-91.

48. Weber CF, Gorlinger K, Meininger D, et al. Point-of-Care Testing: A Prospective, Randomized Clinical Trial of Efficacy in Coagulopathic Cardiac Surgery Patients. Anesthesiology 2012;117:531-47.

49. Rahe-Meyer N, Solomon C, Hanke A, et al. Effects of Fibrinogen Concentrate as First-line Therapy during Major Aortic Replacement Surgery: A Randomized, Placebo-controlled Trial. Anesthesiology 2013;118:40-50. 
50. Ranucci M, Baryshnikova E, Crapelli GB, et al. Randomized, doubleblinded, placebo-controlled trial of fibrinogen concentrate supplementation after complex cardiac surgery. J Am Heart Assoc 2015;4.

51. Karlsson M, Ternstrom L, Hyllner M, et al. Prophylactic fibrinogen infusion reduces bleeding after coronary artery bypass surgery. A prospective randomised pilot study. Thrombosis and haemostasis 2009;102:137-44.

52. Sadeghi M, Atefyekta $R$, Azimaraghi $O$, et al. A randomized, double blind trial of prophylactic fibrinogen to reduce bleeding in cardiac surgery. Brazilian journal of anesthesiology 2014;64:253-7.

53. Tanaka KA, Egan K, Szlam F, et al. Transfusion and hematologic variables after fibrinogen or platelet transfusion in valve replacement surgery: preliminary data of purified lyophilized human fibrinogen concentrate versus conventional transfusion. Transfusion 2014;54:109-18.

54. Solomon C, Hagl C, Rahe-Meyer N. Time course of haemostatic effects of fibrinogen concentrate administration in aortic surgery. British journal of anaesthesia 2013;110:947-56.

55. Bolliger D, Tanaka KA. Roles of thrombelastography and thromboelastometry for patient blood management in cardiac surgery. Transfusion medicine reviews 2013;27:213-20.

56. Nakayama Y, Nakajima Y, Tanaka KA, et al. Thromboelastometry-guided intraoperative haemostatic management reduces bleeding and red cell transfusion after paediatric cardiac surgery. British journal of anaesthesia 2015;114:91-102.

57. Karkouti K, McCluskey SA, Callum J, et al. Evaluation of a Novel Transfusion Algorithm Employing Point-of-care Coagulation Assays in Cardiac Surgery: A Retrospective Cohort Study with Interrupted TimeSeries Analysis. Anesthesiology 2015;122:560-70.

58. Kirchner C, Dirkmann D, Treckmann JW, et al. Coagulation management with factor concentrates in liver transplantation: a single-center experience. Transfusion 2014;54:2760-8.

59. Tripodi A, Mannucci PM. The coagulopathy of chronic liver disease. The New England journal of medicine 2011;365:147-56.

60. Roullet S, Freyburger G, Cruc M, et al. Management of bleeding and transfusion during liver transplantation before and after the introduction of a rotational thromboelastometry-based algorithm. Liver Transpl 2015;21:169-79.

61. Roullet S, Pillot J, Freyburger G, et al. Rotation thromboelastometry detects thrombocytopenia and hypofibrinogenaemia during orthotopic liver transplantation. British journal of anaesthesia 2010;104:422-8. 
62. Tripodi A, Primignani M, Chantarangkul V, et al. The coagulopathy of cirrhosis assessed by thromboelastometry and its correlation with conventional coagulation parameters. Thrombosis research 2009;124:1326.

63. Clevenger B, Mallett SV. Transfusion and coagulation management in liver transplantation. World journal of gastroenterology : WJG 2014;20:6146-58.

64. Rana A, Petrowsky $\mathrm{H}$, Hong $\mathrm{JC}$, et al. Blood transfusion requirement during liver transplantation is an important risk factor for mortality. Journal of the American College of Surgeons 2013;216:902-7.

65. Kang YG, Martin DJ, Marquez J, et al. Intraoperative changes in blood coagulation and thrombelastographic monitoring in liver transplantation. Anesthesia and analgesia 1985;64:888-96.

66. Leon-Justel A, Noval-Padillo JA, Alvarez-Rios Al, et al. Point-of-care haemostasis monitoring during liver transplantation reduces transfusion requirements and improves patient outcome. Clinica chimica acta; international journal of clinical chemistry 2015;446:277-83.

67. Khan KS, Wojdyla D, Say L, Gulmezoglu AM, Van Look PF. WHO analysis of causes of maternal death: a systematic review. Lancet 2006;367:106674.

68. Hogan MC, Foreman KJ, Naghavi M, et al. Maternal mortality for 181 countries, 1980-2008: a systematic analysis of progress towards Millennium Development Goal 5. Lancet 2010;375:1609-23.

69. Kramer MS, Berg C, Abenhaim $\mathrm{H}$, et al. Incidence, risk factors, and temporal trends in severe postpartum hemorrhage. American journal of obstetrics and gynecology 2013;209:449 e1-7.

70. Prick BW, Auf Altenstadt JF, Hukkelhoven CW, et al. Regional differences in severe postpartum hemorrhage: a nationwide comparative study of 1.6 million deliveries. BMC pregnancy and childbirth 2015;15:43.

71. Abdul-Kadir R, McLintock C, Ducloy AS, et al. Evaluation and management of postpartum hemorrhage: consensus from an international expert panel. Transfusion 2014;54:1756-68.

72. Ekelund K, Hanke G, Stensballe J, Wikkelsoe A, Albrechtsen CK, Afshari A. Hemostatic resuscitation in postpartum hemorrhage - a supplement to surgery. Acta obstetricia et gynecologica Scandinavica 2015;94:680-92.

73. Ducloy-Bouthors AS, Jude B, Duhamel A, et al. High-dose tranexamic acid reduces blood loss in postpartum haemorrhage. Crit Care 2011;15:R117.

74. Shakur H, Elbourne D, Gulmezoglu M, et al. The WOMAN Trial (World Maternal Antifibrinolytic Trial): tranexamic acid for the treatment of postpartum haemorrhage: an international randomised, double blind placebo controlled trial. Trials 2010;11:40. 
75. Charbit B, Mandelbrot L, Samain E, et al. The decrease of fibrinogen is an early predictor of the severity of postpartum hemorrhage. J Thromb Haemost 2007;5:266-73.

76. Karlsson O, Jeppsson A, Thornemo M, Lafrenz H, Radstrom M, Hellgren M. Fibrinogen plasma concentration before delivery is not associated with postpartum haemorrhage: a prospective observational study. British journal of anaesthesia 2015;115:99-104.

77. Ahmed S, Harrity C, Johnson S, et al. The efficacy of fibrinogen concentrate compared with cryoprecipitate in major obstetric haemorrhage--an observational study. Transfusion medicine (Oxford, England) 2012;22:344-9.

78. Wikkelso AJ, Edwards HM, Afshari A, et al. Pre-emptive treatment with fibrinogen concentrate for postpartum haemorrhage: randomized controlled trialdagger. British journal of anaesthesia 2015;114:623-33.

79. Abbassi-Ghanavati M, Greer LG, Cunningham FG. Pregnancy and laboratory studies: a reference table for clinicians. Obstetrics and gynecology 2009;114:1326-31.

80. Aawar N, Alikhan R, Bruynseels D, et al. Fibrinogen concentrate versus placebo for treatment of postpartum haemorrhage: study protocol for a randomised controlled trial. Trials 2015;16:169.

81. Girard T, Mortl M, Schlembach D. New approaches to obstetric hemorrhage: the postpartum hemorrhage consensus algorithm. Current opinion in anaesthesiology 2014;27:267-74.

82. Schlembach D, Mortl MG, Girard T, et al. [Management of postpartum hemorrhage (PPH): algorithm of the interdisciplinary D-A-CH consensus group PPH (Germany - Austria - Switzerland)]. Anaesthesist 2014;63:23442.

83. Beyerle A, Nolte MW, Solomon C, Herzog E, Dickneite G. Analysis of the safety and pharmacodynamics of human fibrinogen concentrate in animals. Toxicology and applied pharmacology 2014;280:70-7.

84. Solomon C, Groner A, Ye J, Pendrak I. Safety of fibrinogen concentrate: analysis of more than 27 years of pharmacovigilance data. Thrombosis and haemostasis 2015;113:759-71.

85. Rana R, Fernandez-Perez ER, Khan SA, et al. Transfusion-related acute lung injury and pulmonary edema in critically ill patients: a retrospective study. Transfusion 2006;46:1478-83. 


\section{Conflict-of-interest statement (past 5 years): Donat R. Spahn}

Dr. Spahn's academic department is receiving grant support from the Swiss National Science Foundation, Berne, Switzerland, the Ministry of Health (Gesundheitsdirektion) of the Canton of Zurich, Switzerland for Highly Specialized Medicine, the Swiss Society of Anesthesiology and Reanimation (SGAR), Berne, Switzerland, the Swiss Foundation for Anesthesia Research, Zurich, Switzerland, Bundesprogramm Chancengleichheit, Berne, Switzerland, CSL Behring, Berne, Switzerland, Vifor SA, Villars-sur-Glâne, Switzerland.

Dr. Spahn was the chairman of the ABC Faculty and is the co-chairman of the ABC-Trauma Faculty, which both are managed by Physicians World Europe $\mathrm{GmbH}$, Mannheim, Germany and sponsored by unrestricted educational grants from Novo Nordisk Health Care AG, Zurich, Switzerland, CSL Behring GmbH, Marburg, Germany and LFB Biomédicaments, Courtaboeuf Cedex, France.

In the past 5 years, Dr. Spahn has received honoraria or travel support for consulting or lecturing from the following companies: Abbott AG, Baar, Switzerland, AMGEN GmbH, Munich, Germany, AstraZeneca AG, Zug, Switzerland, Bayer (Schweiz) AG, Zürich, Switzerland, Baxter AG, Volketswil, Switzerland, Baxter S.p.A., Roma, Italy, B. Braun Melsungen AG, Melsungen, Germany, Boehringer Ingelheim (Schweiz) $\mathrm{GmbH}$, Basel, Switzerland, Bristol-Myers-Squibb, RueilMalmaison Cedex, France and Baar, Switzerland, CSL Behring $\mathrm{GmbH}$, Hattersheim am Main, Germany and Berne, Switzerland, Curacyte AG, Munich, Germany, Daiichi Sankyo (Schweiz) AG, Thalwil, Switzerland, Ethicon Biosurgery, Sommerville, New Jersey, USA, Fresenius SE, Bad Homburg v.d.H., Germany, Galenica AG, Bern, Switzerland (including Vifor SA, Villars-sur-Glâne, Switzerland), GlaxoSmithKline GmbH \& Co. KG, Hamburg, Germany, JanssenCilag AG, Baar, Switzerland, Janssen-Cilag EMEA, Beerse, Belgium, Merck Sharp \& Dohme AG, Luzern, Switzerland, Novo Nordisk A/S, Bagsvärd, Denmark, Octapharma AG, Lachen, Switzerland, Organon AG, Pfäffikon/SZ, Switzerland, Oxygen Biotherapeutics, Costa Mesa, CA, Photonics Healthcare B.V., Utrecht, Netherlands, ratiopharm Arzneimittel Vertriebs-GmbH, Vienna, Austria, 
Roche Diagnostics International Ltd, Reinach, Switzerland, Roche Pharma (Schweiz) AG, Reinach, Switzerland, Schering-Plough International, Inc., Kenilworth, New Jersey, USA, Tem International GmbH, Munich, Germany, Verum Diagnostica $\mathrm{GmbH}$, Munich, Germany, Vifor Pharma Deutschland $\mathrm{GmbH}$, Munich, Germany, Vifor Pharma Österreich GmbH, Vienna, Austria, Vifor (International) AG, St. Gallen, Switzerland.

\section{Gabriela H. Spahn}

No conflicts of interest to be declared

\section{Philipp Stein}

No conflicts of interest to be declared 
Table 1: Trigger values for the administration of fibrinogen concentrate in different clinical settings. Please note that the algorithms in the various studies were not limited to the administration of fibrinogen. They also contained information on the monitoring of coagulation and the indication for other coagulation products including (in most) the use of allogeneic blood products (RBC, plasma and platelets).

\begin{tabular}{|c|c|c|c|}
\hline Clinical setting & Trigger & Fibrinogen dose & Reference \\
\hline Trauma & FIBTEM MCF $\leq 7 \mathrm{~mm}$ & $2-4 \mathrm{~g}$ & Nardi et al. ${ }^{15}$ \\
\hline Trauma & FIBTEM MCF $\leq 10 \mathrm{~mm}$ & $2-4 \mathrm{~g}$ & Schöchl et al. ${ }^{17}$ \\
\hline Trauma & FIBTEM MCF $<7 \mathrm{~mm}$ & $2-4 \mathrm{~g}$ & Theusinger et al. ${ }^{26}$ \\
\hline Trauma & Fibrinogen $<1.5-2 \mathrm{~g} / \mathrm{L}$ & $3-4 \mathrm{~g}$ & Spahn et al. ${ }^{20}$ \\
\hline Trauma & Fibrinogen $<1.5-2 \mathrm{~g} / \mathrm{L}$ & $2-4 \mathrm{~g}$ & Nienaber et al. ${ }^{44}$ \\
\hline Trauma & FIBTEM A10 < $7 \mathrm{~mm}$ & $3-8 g$ & Schöchl et al. ${ }^{46}$ \\
\hline Cardiac surgery & $\begin{array}{l}\text { FIBTEM A10 } \leq 10 \mathrm{~mm} \\
\text { (early after CPB) } \\
\text { or } \\
\text { FIBTEM A } 10<15 \mathrm{~mm} \\
\text { (late ongoing bleeding) }\end{array}$ & $25-50(75) \mathrm{mg} / \mathrm{kg}$ & Görlinger et al. ${ }^{47}$ \\
\hline Cardiac surgery & $\begin{array}{l}\text { FIBTEM A10 } \leq 10 \mathrm{~mm} \\
\text { (early after CPB) } \\
\text { or } \\
\text { FIBTEM A10 < } 15 \mathrm{~mm} \\
\text { (late ongoing bleeding) }\end{array}$ & $25-50(75) \mathrm{mg} / \mathrm{kg}$ & Weber et al. ${ }^{48}$ \\
\hline Cardiac surgery (CABG) & Prophylactic preoperatively & $2 \mathrm{~g}$ & Karlsson et al. ${ }^{51}$ \\
\hline Cardiac surgery (CABG) & Prophylactic preoperatively & $1 \mathrm{~g}$ & Sadeghi et al. ${ }^{52}$ \\
\hline $\begin{array}{l}\text { Cardiac surgery (valve re- } \\
\text { placement) }\end{array}$ & Moderate bleeding & $4 \mathrm{~g}$ fibrinogen & Tanaka et al. ${ }^{53}$ \\
\hline
\end{tabular}




\begin{tabular}{|c|c|c|c|}
\hline Cardiac surgery (pediatric) & FIBTEM A10 $\leq 5 \mathrm{~mm}$ & $20 \mathrm{ml} / \mathrm{kg}$ FFP & Nakayama et al. ${ }^{56}$ \\
\hline Liver transplantation & FIBTEM MCF $\leq 6 \mathrm{~mm}$ & $\mathrm{n} / \mathrm{a}$ & Kirchner et al. ${ }^{58}$ \\
\hline Liver transplantation & $\begin{array}{l}\text { FIBTEM MCF } \leq 6 \mathrm{~mm} \\
\text { or } \\
\text { Fibrinogen }<1 \mathrm{~g} / \mathrm{L}\end{array}$ & $50 \mathrm{mg} / \mathrm{kg}$ & Roullet et al. ${ }^{60}$ \\
\hline Obstetric & Fibrinogen $<2 \mathrm{~g} / \mathrm{L}$ & $\mathrm{n} / \mathrm{a}$ & Abdul-Kadir et al. ${ }^{71}$ \\
\hline Obstetric & Fibrinogen $\leq 2 \mathrm{~g} / \mathrm{L}$ & $4 \mathrm{~g}$ & Ahmed et al. ${ }^{77}$ \\
\hline Obstetric & $\begin{array}{l}\text { Severe PPH with blood } \\
\text { loss of }>1 \text { liter }\end{array}$ & $2 \mathrm{~g}$ & Wikkelso et al. ${ }^{78}$ \\
\hline Obstetric & Fibrinogen $<1.5 \mathrm{~g} / \mathrm{L}$ & $2-4 g$ & Girard et al. ${ }^{81}$ \\
\hline Obstetric & $\begin{array}{l}\text { FIBTEM A5 }<7 \mathrm{~mm} \\
\text { or } \\
\text { Fibrinogen } \leq 1.5 \mathrm{~g} / \mathrm{L}\end{array}$ & $3 \mathrm{~g}$ initial dose & Mallaiah et al. ${ }^{10}$ \\
\hline General & Fibrinogen $<1.5-2 \mathrm{~g} / \mathrm{L}$ & $25-50 \mathrm{mg} / \mathrm{kg}$ & Kozek-Langenecker et al. ${ }^{42}$ \\
\hline General pediatric surgery & $\begin{array}{l}\text { FIBTEM MCF }<7 \mathrm{~mm} \\
\text { or } \\
\text { Fibrinogen }<1.5-2 \mathrm{~g} / \mathrm{L}\end{array}$ & $30-50 \mathrm{mg} / \mathrm{kg}$ & Kozek-Langenecker et al. ${ }^{42}$ \\
\hline General & Fibrinogen $\leq 2 \mathrm{~g} / \mathrm{L}$ & $1-2 \mathrm{~g}$ & Fenger-Eriksen et al. ${ }^{14}$ \\
\hline
\end{tabular}

